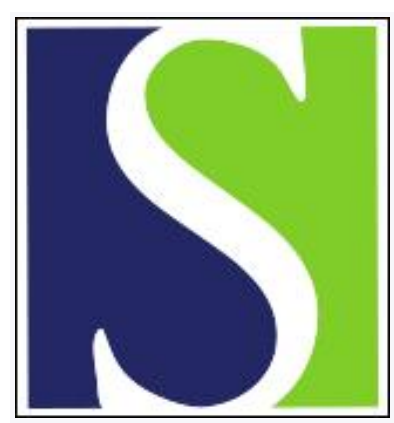

Scand J Work Environ Health 1984;10(5):283-291

https://doi.org/10.5271/sjweh.2329

Issue date: Oct 1984

Mortality among asbestos-exposed workers in a railroad workshop.

by Ohlson CG, Klaesson B, Hogstedt C

This article in PubMed: www.ncbi.nlm.nih.gov/pubmed/6098009

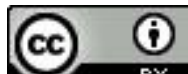




\title{
Mortality among asbestos-exposed workers in a railroad workshop
}

\author{
by Carl-Göran OhIson, MD, ${ }^{1,2}$ Birgitta Klaesson, ${ }^{1}$ Christer Hogstedt, MD $^{3,4}$
}

\begin{abstract}
OHLSON C-G, KLAESSON B, HOGSTEDT C. Mortality among asbestos-exposed workers in a railroad workshop. Scand J Work Environ Health 10 (1984) 283-291. The mortality experience of a cohort of 3297 railroad maintenance shopworkers exposed to asbestos was investigated. The study period was $1951-1980$, and the vital status was assessed for $99.6 \%$ of the men. Individual estimates of cumulative asbestos exposure were based on detailed records on work tasks and divisions. Dust measurements were scanty in earlier decades, and estimates of average fiber levels were therefore based on information on the amount and kind of asbestos used, job descriptions, and interviews with older workers. The overall mortality was lower than expected from the national death rates (standardized mortality ratio $=82$ ). The mortality from lung cancer increased as cumulative exposure increased in consistent dose-response relationships. Employment times of less than 30 years in workplaces with moderate levels of mainly chrysotile asbestos was not associated with any apparent increase in the risk of lung cancer. A subgroup exposed for more than 30 years in workplaces repairing steam engines, where amphiboles were used as well, had a standardized mortality ratio of 192 for lung cancer. This figure may be an underestimation due to healthy worker selection and fewer smokers than normal. The "true" standardized mortality ratio was estimated to be about 300 . Five cases of mesothelioma were observed.
\end{abstract}

Key terms: amphiboles, chrysotile, cohort study, lung cancer, steam engines.

More than 3000 papers on the biological effects of asbestos fibers have been published (12), and epidemiologic studies have demonstrated an increased risk for lung cancer in groups exposed occupationally to asbestos. However, information on risks at various degrees of exposure is given in only a dozen studies (10), and many of the exposure estimates are incomplete regarding cumulative exposure and type of asbestos fibers. The exposure-response relation estimates reported from different studies vary considerably.

The aim of this study was to estimate the overall risk of lung cancer among asbestos-exposed railroad maintenance shop workers and the risk in subcategories according to exposure indices and years of employment. Furthermore an attempt has been made to elucidate the impact of different types of asbestos, ie, amphibole and serpentine.

1 Department of Occupational Medicine, Medical Center Hospital, Örebro, Sweden.

2 Department of Occupational Medicine, Linköping University, Linköping, Sweden.

3 Department of Occupational Medicine, Karolinska Hospital, Stockholm, Sweden.

4 Department of Occupational Medicine, National Board of Occupational Safety and Health, Solna, Sweden.

Reprint requests to: Dr C-G Ohlson, Department of Occupational Medicine, Medical Center Hospital, S-701 85 Örebro, Sweden.

\section{Materials and methods}

\section{Source population}

The railroad workshop for the repair and maintenance of engines, railcars, passenger coaches, and rail switches started in 1902 . The enterprise expanded during and after the Second World War. In 1949 the number of employees was 1650 , but it decreased during the following decades, to about $620 \mathrm{em}$ ployees by 1980 , due to rationalizations. In all, around 5000 men have been employed sometime during the period 1902-1980. Detailed records on work tasks and divisions are available for every man.

\section{Study population and employment conditions}

The study population was restricted to all men hired by the enterprise for three weeks or longer during the period 1939-1980, a total of 3442 persons. The distribution of the employment times is displayed in figure $1-56 \%$ had been employed for more than 10 years and only $16 \%$ for less than one year. The workers used to stick to a specific division, and changes, eg, from the steam engine division to the passenger-coach division, were not common. Before the middle of the 1950 s special permission was required for a person to pass through other divisions. Furthermore, for a long time, the requirements for employment demanded that persons to be employed should be in good health; have a good sense of hearing, straight posture, and military service fulfilled; and be no more than 24 years of age. 


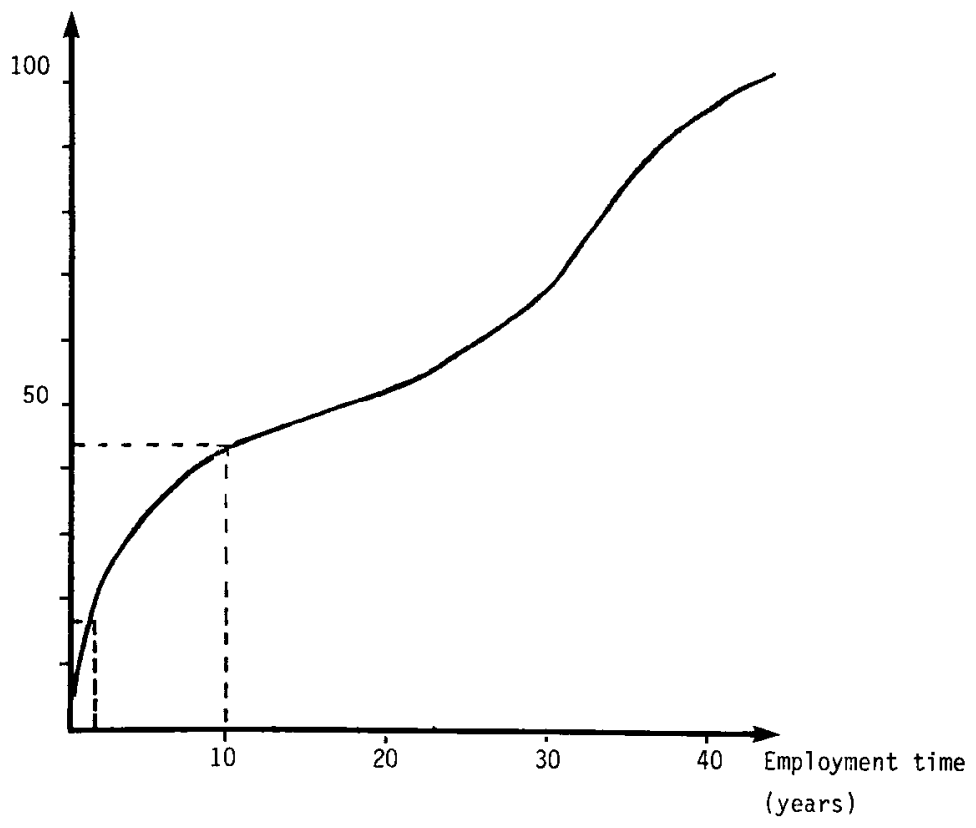

Figure 1. Distribution of the employment times (median $=16$ years).

\section{Vital status of the cohort members}

The study population consisted of 3442 men, and their vital status was traced through several sources, as displayed in figure 2. Some 2196 subjects were found through the National Health Service, which keeps records of all living persons in Sweden by a tendigit identification number based on time of birth. The remaining 1246 were checked through other public population registers, and the death and burial books of the parishes. Three men had emigrated. Information on address was missing or obviously wrong for 205 subjects, but 191 could be traced through local registers. Only five of these men were alive.

In total, the vital status of the study population could be assessed for $99.6 \%$ of the subjects, and the remaining 14 subjects were excluded from the calculations, thus based on 3297 subjects.

Death certificates and thereby the officially classified underlying cause of death (15) was obtained for 848 of 925 men deceased in 1951-1980, which was chosen as the study period. Valid classification according to rules of the World Health Organization for underlying causes of death were introduced in 1951. This procedure excluded 128 men who had died before 1951. The death certificates could not be found for $38 \mathrm{men}$, and for them the underlying causes of death were coded from the diagnoses given in the death and burial books according to the same classification rules.

The expected number of deaths was calculated by the multiplication of the person-years of observation within five-year age categories during respective single calendar years of the study period by the cause-, gender- and calendar year-specific national death rates. The relative risks were calculated with a requirement of 20 years' latency time for the total cohort, as well as for the subcohorts of different exposure categories, ie, the time from first exposure to the beginning of the individual observation period under risk. A computer program - EPILIN - developed at the University of Linköping for calculating expected numbers and relative risks with $95 \%$ confidence intervals was used (2).

The relative risk, ie, the ratio between observed and expected numbers, or the standardized mortality ratio (SMR), is reported for all causes of death, lung cancer, gastrointestinal cancer, and nonmalignant respiratory diseases. Chronic obstructive lung disease could mainly be assumed to reflect smoking habits and is therefore shown separately.

\section{Exposure}

\section{Steam engines}

Asbestos has been used as insulation material at the workshop since 1902 . In the 1920 s and 1930s special padded insulation, so-called mattresses, containing crocidolite was used. During the Second World War these mattresses were filled with chrysotile. "Magnesia lagging," which was probably a mixture of amosite and magnesia, was periodically used as a substitution for mattresses. This "lagging" was enforced by firm sheets of chrysotile and with wire nets wound around the steam boiler. As there was a 
lack of imported asbestos during the Second World War, mineral wool was used as a substitute.

The steam boilers were maintenanced regularly, in general every sixth year, and broken up after 25 years of service.
During the maintenance of the steam boiler the insulation material was loosened, and some of the padded asbestos could be torn and spread around. After being dismantled, the steam boiler was carried to the platers' shop, where the remaining asbestos

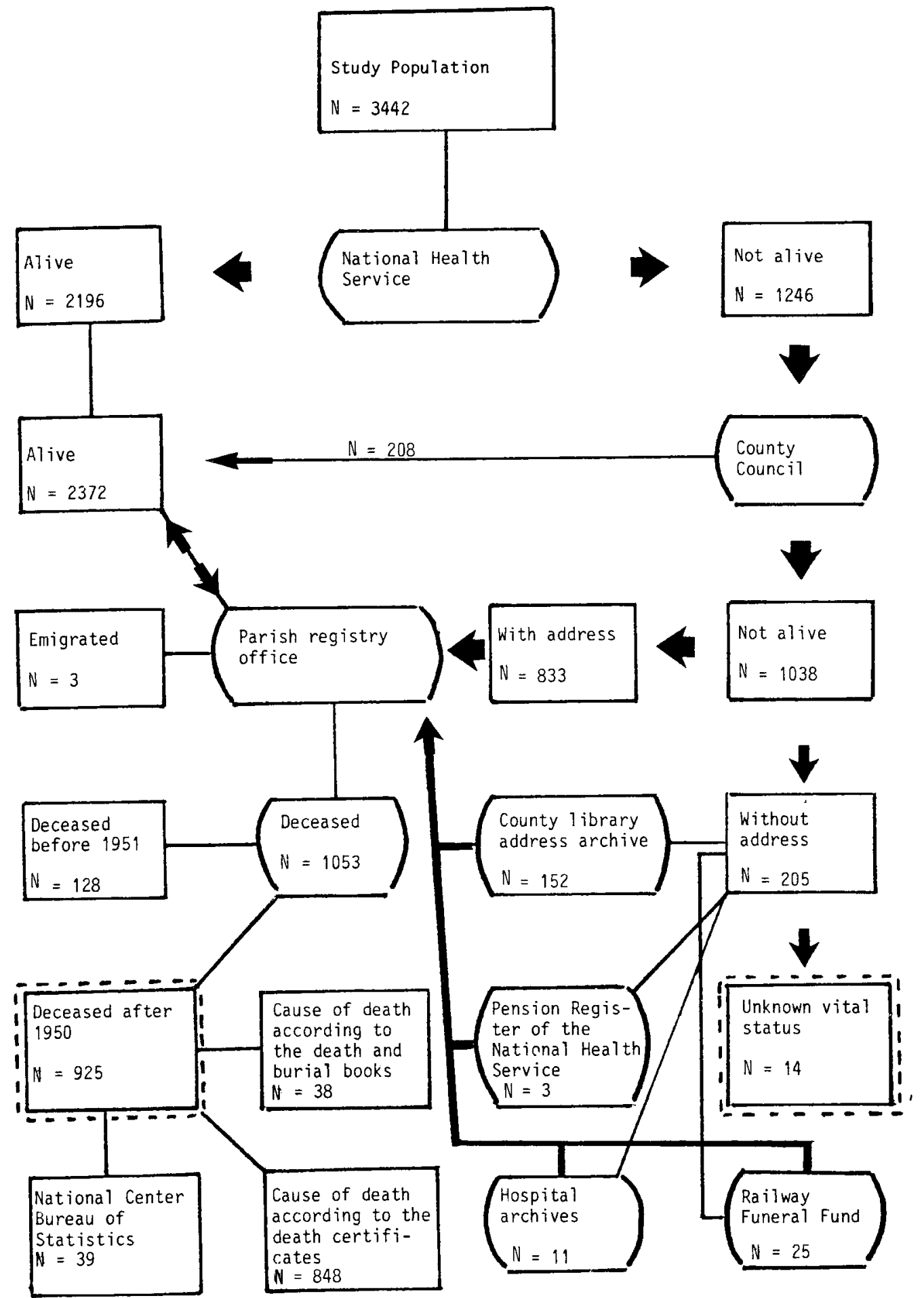

Figure 2. The process of tracing 3442 cohort members through various registers. 
was brushed away with long brushes of steel. According to statements from several old workers this part of the shop was very dusty and caused rays in the light from the windows in the ceiling. It has, however, not been possible to assess the amount of crocidolite from torn mattresses. The asbestos material that was brushed away was probably mostly amosite and chrysotile.

It seems likely that the mattresses containing crocidolite could have appeared in the shop as late as 1950. During the first half of the 1950s the steam engines were gradually replaced by electric ones, and the last steam engine passed through the maintenance shop in 1955 .

Table 1. Conversions of arbitrary dust scores to fiber levels.

\begin{tabular}{ccc}
\hline \multirow{2}{*}{ Dust score } & \multicolumn{2}{c}{ Fiber/ml } \\
\cline { 2 - 3 } & Mode level & Range \\
\hline 0 & 0 & 0 \\
1 & 0.5 & $0.5-1$ \\
2 & 3 & $1-5$ \\
3 & 7 & $5-10$ \\
4 & 15 & $10-20$ \\
\hline
\end{tabular}

\section{Passenger coaches}

The walls of the passenger coaches were spray-insulated with crocidolite during 1961-1971. Before 1961 the coaches were insulated with cork, or with mineral wool, and from 1971 on with polyurethane foam. The heating equipment of the coaches was insulated with yarns of chrysotile wound around the pipes. The exhaust pipes of the motor coaches were also insulated in this way. The main source of dust was caused by the dismantling of old and dry asbestos, particularly when it was shaken and brushed away. The water tanks at the end of the passenger coachs were insulated with crocidolite. The ventilation pipes contained amosite, and amosite mixed with chrysotile was used in the equipment for air conditioning.

\section{Other sources of asbestos exposure}

Some work tasks might have involved high exposure for single individuals but might not have caused any important dissemination of asbestos throughout the shop. Such tasks were the punching of gaskets from sheets of asbestos, the changing of break lines in electric engines, and insulating with asbestos powder

Table 2. Observed and expected numbers of deaths for the total cohort without any restrictions and for a subcohort with 20 years or more after first date of employment (latency time) before the age of 80 years. (SMR = standardized mortality ratio).

\begin{tabular}{|c|c|c|c|c|c|c|}
\hline \multirow{2}{*}{ Cause of death } & \multicolumn{3}{|c|}{ Total cohort } & \multicolumn{3}{|c|}{ Subcohort } \\
\hline & Observed & Expected & SMR & Observed & Expected & SMR \\
\hline All causes & 925 & 1132.6 & 82 & 586 & 727 & 81 \\
\hline All tumors & 199 & 234.6 & 85 & 144 & 166 & 87 \\
\hline Lung cancer & 37 & 31.8 & 116 & 27 & 25.7 & 105 \\
\hline Pancreas cancer & 17 & 15.3 & 111 & 13 & 11.5 & 113 \\
\hline Gastric cancer & 41 & 71.6 & 57 & 30 & 51.1 & 59 \\
\hline Colorectal cancer & 20 & 30.3 & 66 & 15 & 20.9 & 72 \\
\hline Diseases of circulatory system & 489 & 538.9 & 91 & 310 & 339.9 & 91 \\
\hline Ischemic heart disease & 317 & 355.1 & 89 & 210 & 232.4 & 90 \\
\hline Chronic obstructive lung disease & 6 & 16.8 & 36 & 5 & 11.3 & 44 \\
\hline \multicolumn{7}{|l|}{$\begin{array}{l}\text { Diseases of the respiratory tract } \\
\text { (excluding chronic obstructive }\end{array}$} \\
\hline & 48 & 45.9 & 105 & 18 & 22.8 & 79 \\
\hline Violent deaths and poisoning & 62 & 89.1 & 70 & 34 & 51.0 & 67 \\
\hline
\end{tabular}

Table 3. Observed and expected numbers of deaths before the age of 80 years by different employment times and 20 years or dardized mortality ratio)

\begin{tabular}{|c|c|c|c|c|c|c|c|c|c|}
\hline \multirow{3}{*}{ Cause of death } & & & & & & & \multicolumn{3}{|c|}{ Length of employment } \\
\hline & \multicolumn{3}{|c|}{$<2$ years } & \multicolumn{3}{|c|}{$2-4$ years } & \multicolumn{3}{|c|}{$5-14$ years } \\
\hline & Observed & Expected & SMR & Observed & Expected & SMR & Observed & Expected & SMR \\
\hline All causes & 42 & 83.5 & 50 & 20 & 26 & 77 & 43 & 59.1 & 73 \\
\hline Lung cancer & 0 & 3.7 & - & 1 & 1.2 & 83 & 0 & 2.5 & - \\
\hline $\begin{array}{l}\text { Gastric cancer } \\
\text { Chrónic obstructive }\end{array}$ & 0 & 4.9 & - & 1 & 1.6 & 64 & 2 & 3.7 & 54 \\
\hline $\begin{array}{l}\text { Iung disease } \\
\text { Diseases of the } \\
\text { respiratory tract } \\
\text { (excluding chronic } \\
\text { obstructive lung }\end{array}$ & 0 & 1.5 & - & 2 & 0.5 & 377 & 0 & 1.0 & - \\
\hline disease) & 0 & 2.0 & - & 1 & 0.6 & 175 & 0 & 1.5 & - \\
\hline
\end{tabular}


in the casting and insulation of the electrical works of the engines.

\section{Exposure data from the 1970s}

Fiber counts from personal and stationary air samples made with standardized techniques were available in Sweden from 1970 on. During the period 1970 - 1980 the fiber counts were relatively low. Of 64 air samples from this period, only eight yielded counts higher than 1 fiber $/ \mathrm{ml}$. However, the measurements at this workshop aimed at giving evidence of improvements initiated by the industrial health organization rather than at being representative of the exposure situation.

\section{Exposure in different divisions}

The estimations of the exposure in the various divisions of the workshop were performed in consultation with a reference group of representatives from the staff management, the local trade union, and a former supervisor who had experience of the work practices in the $1940 \mathrm{~s}$ and $1950 \mathrm{~s}$. The estimates were based on information on the intensity of production, the amount and kind of asbestos used during various periods, and a detailed report by the industrial health organization on the handling of asbestos. Furthermore, descriptions and recollections by exemployees were taken into account in estimates of the exposure of various work tasks, the distance between the worker and various dust sources, and the impact on other divisions from air contamination.

With all these factors taken together, an individual classification of the exposure intensity for every year could be achieved. The intensity was graded according to an ordinal scale with scores from 0 to 4 according to the following criteria:

$$
\begin{aligned}
& 0-\text { no asbestos exposure } \\
& 1-\text { irregular exposure of low intensity } \\
& 2-\text { regular, low exposure }
\end{aligned}
$$

nore after the first date of employment (latency time) (SMR = stan-

\begin{tabular}{rrrrrrrr}
\hline \multicolumn{3}{c}{$15-29$ years } & & \multicolumn{3}{c}{$\geq 30$ years } \\
\cline { 6 - 7 } Ibserved & Expected & SMR & & Observed & Expected & SMR \\
\hline 166 & 148.0 & 112 & & 315 & 410.4 & 77 \\
6 & 5.4 & 112 & & 20 & 13.0 & 154 \\
10 & 10.5 & 96 & & 17 & 30.4 & 56 \\
1 & 2.4 & 42 & & 2 & 5.9 & 34
\end{tabular}

3 - medium exposure

4 - heavy exposure

This basis for classifying exposure differs from the commonly applied practice of using data from dust samples. As there is no reliable factor of conversion from dust measurements as milligrams per milliliter or millions of particles per cubic foot to fibers per milliliter (6), the air concentrations in different parts of the shop have been related to other trades with known fiber concentrations. American insulators form the basis for comparison with other trades in an extensive report (11). The workers with the highest exposure in the railroad maintenance shops, ie, those working with the insulation of steam engines and passenger coaches, were estimated in this report to be as heavily exposed as insulators with a historical exposure of around 10-20 fibers $/ \mathrm{ml}$, on the average (9).

The exposure in the workshop of the present study was estimated to have been about $3-5$ fibers $/ \mathrm{ml}$, on the average, during previous decades. This level would correspond to regular low-medium exposure, ie, to a dust score of 2 or 3 . The exposure of the men who worked with steam engines and passenger coaches, ie, heavy exposure estimated at 10-20 fibers $/ \mathrm{ml}$, would consequently correspond to a dust score of 4 . Attempts to reach a crude conversion to fiber counts is displayed in table 1 .

Information on the employment times and the dust scores of every division during the respective calendar year for every cohort member form the basis for the exposure categories. Two aspects of the exposure are elucidated, cumulative exposure, eg, the sum of all employment times multiplied by the dust scores and the number of years in highly exposed work, eg, dust scores 3 and 4 .

\section{Results}

The overall mortality for the whole cohort was lower than expected from the national death rates, SMR = 82 (table 2). The same tendency towards decreased mortality was seen for gastrointestinal cancer and nonmalignant diseases of the respiratory tract, especially for the subgroup chronic obstructive lung disease (SMR $=36)$. However, the relative risk for lung cancer was increased (SMR $=116)$.

The mortality pattern was basically the same with a requirement of 20 years of latency and follow-up only to 79 years of age (table 2).

A subcohort of men employed for 30 years displayed an increased risk for lung cancer, $\mathrm{SMR}=154$ (table 3). Neither the risk of overall mortality nor specific causes of death were influenced to any appreciable extent by the length of employment, except for that of short-term. Among men employed 15-30 years, the overall mortality was higher than within the other strata because of an excess mortality from ischemic heart disease. 
Table 4. Observed and expected numbers of deaths before the age of 80 years by various cumulative exposures as the score $x$ years and 20 years or more after the first date of employment (latency time). (SMR = standardized mortality ratio)

\begin{tabular}{|c|c|c|c|c|c|c|c|c|c|c|c|c|}
\hline \multirow{3}{*}{ Cause of death } & \multicolumn{12}{|c|}{ Exposure intensity score $\times$ length of employment } \\
\hline & \multicolumn{3}{|c|}{$<25$} & \multicolumn{3}{|c|}{$25-49$} & \multicolumn{3}{|c|}{$50-74$} & \multicolumn{3}{|c|}{$\geq 75$} \\
\hline & $\begin{array}{l}\text { Ob- } \\
\text { served }\end{array}$ & $\begin{array}{c}\text { Ex- } \\
\text { pected }\end{array}$ & SMR & $\begin{array}{c}\text { Ob- } \\
\text { served }\end{array}$ & $\begin{array}{c}\text { Ex- } \\
\text { pected }\end{array}$ & SMR & $\begin{array}{l}\text { Ob- } \\
\text { served }\end{array}$ & $\begin{array}{c}\text { Ex- } \\
\text { pected }\end{array}$ & SMR & $\begin{array}{c}\text { Ob- } \\
\text { served }\end{array}$ & $\begin{array}{c}\text { Ex- } \\
\text { pected }\end{array}$ & SMR \\
\hline All causes & 104 & 168.0 & 62 & 75 & 93.3 & 80 & 121 & 139.2 & 87 & 286 & 326.6 & 88 \\
\hline Lung cancer & 2 & 7.5 & 27 & 2 & 3.7 & 53 & 6 & 4.5 & 134 & 17 & 10.0 & 162 \\
\hline $\begin{array}{l}\text { Gastric cancer } \\
\text { Chronic obstructive }\end{array}$ & 3 & 10.2 & 29 & 6 & 6.2 & 96 & 7 & 10.1 & 69 & 14 & 24.6 & 57 \\
\hline $\begin{array}{l}\text { lung disease } \\
\text { Diseases of the } \\
\text { respiratory tract } \\
\text { (excluding chronic } \\
\text { obstructive lung }\end{array}$ & 2 & 3.0 & 66 & 0 & 1.6 & - & 1 & 2.0 & 50 & 2 & 4.6 & 43 \\
\hline disease) & 1 & 3.9 & 25 & 1 & 2.6 & 39 & 5 & 4.7 & 106 & 11 & 11.7 & 94 \\
\hline
\end{tabular}

Table 5. Observed and expected numbers of deaths before the age of 80 years by different number of years in heavily exposed work ( $=\geq 3$ dust score) and 20 years or more after the first date of employment (latency time). (SMR = standardized mortality ratio)

\begin{tabular}{|c|c|c|c|c|c|c|c|c|c|c|c|c|}
\hline \multirow{3}{*}{ Cause of death } & \multicolumn{12}{|c|}{ Years in heavily exposed work } \\
\hline & \multicolumn{3}{|c|}{$<5$} & \multicolumn{3}{|c|}{$5-9$} & \multicolumn{3}{|c|}{$10-24$} & \multicolumn{3}{|c|}{$\geq 25$} \\
\hline & $\begin{array}{c}\text { Ob- } \\
\text { served }\end{array}$ & $\begin{array}{c}\text { Ex- } \\
\text { pected }\end{array}$ & SMR & $\begin{array}{l}\text { Ob- } \\
\text { served }\end{array}$ & $\begin{array}{c}\text { Ex- } \\
\text { pected }\end{array}$ & SMR & $\begin{array}{l}\text { Ob- } \\
\text { served }\end{array}$ & $\begin{array}{c}\text { Ex- } \\
\text { pected }\end{array}$ & SMR & $\begin{array}{l}\text { Ob- } \\
\text { served }\end{array}$ & $\begin{array}{c}\text { Ex- } \\
\text { pected }\end{array}$ & SMR \\
\hline All causes & 161 & 221 & 73 & 234 & 260 & 90 & 23 & 23.4 & 98 & 163 & 211.6 & 77 \\
\hline Lung cancer & 4 & 8.6 & 47 & 9 & 8.8 & 102 & 1 & 1 & 100 & 13 & 6.9 & $189^{*}$ \\
\hline Gastric cancer & 8 & 14.6 & 55 & 12 & 18.8 & 64 & 2 & 1.5 & 130 & 8 & 15.5 & 52 \\
\hline $\begin{array}{l}\text { Chronic obstructive } \\
\text { lung disease } \\
\text { Diseases of the } \\
\text { respiratory tract } \\
\text { (excluding chronic } \\
\text { obstructive lung }\end{array}$ & 2 & 3.7 & 55 & 1 & 4.0 & 25 & 0 & 0.9 & - & 1 & 3.1 & 33 \\
\hline disease) & 1 & 6.3 & 16 & 9 & 8.5 & 106 & 2 & 1.4 & 140 & 7 & 7.1 & 99 \\
\hline
\end{tabular}

* $p=0.05(95 \%$ confidence interval $1.00-3.22)$.

Table 6. Observed and expected numbers of deaths before the age of 80 years by different periods of employment and 20 years or more after the first date of employment (latency time). (SMR = standardized mortality ratio)

\begin{tabular}{|c|c|c|c|c|c|c|c|c|c|}
\hline \multirow[b]{2}{*}{ Cause of death } & \multicolumn{3}{|c|}{ Employed before 1939} & \multicolumn{3}{|c|}{ Employed in 1939-1954 } & \multicolumn{3}{|c|}{ Employed after 1954} \\
\hline & $\begin{array}{c}\text { Ob- } \\
\text { served }\end{array}$ & $\begin{array}{c}\text { Ex- } \\
\text { pected }\end{array}$ & SMR & $\begin{array}{l}\text { Ob- } \\
\text { served }\end{array}$ & $\begin{array}{c}\text { Ex- } \\
\text { pected }\end{array}$ & SMR & $\begin{array}{l}\text { Ob- } \\
\text { served }\end{array}$ & $\begin{array}{c}\text { Ex- } \\
\text { pected }\end{array}$ & SMR \\
\hline All causes & 432 & 483 & 89 & 69 & 107.5 & 64 & 6 & 8.1 & 74 \\
\hline Lung cancer & 27 & 14.4 & $188^{*}$ & 0 & 4.7 & - & 0 & 0.4 & - \\
\hline Gastric cancer & 25 & 36.7 & 74 & 1 & 6.4 & 16 & 1 & 0.4 & 238 \\
\hline $\begin{array}{l}\text { Chronic obstructive } \\
\text { lung disease }\end{array}$ & 2 & 6.8 & 29 & 1 & 1.9 & 53 & 1 & 0.2 & 650 \\
\hline $\begin{array}{l}\text { Diseases of the } \\
\text { respiratory tract } \\
\text { (excluding chronic } \\
\text { obstructive lung } \\
\text { disease) }\end{array}$ & 16 & 17.5 & 91 & 1 & 2.6 & 38 & 0 & 0.2 & - \\
\hline
\end{tabular}

* $p<0.05(95 \%$ confidence interval $1.23-2.73)$.

Cumulative exposure as the basis for categorization yielded a more marked dose-response relationship, the SMR for lung cancer increasing from 27 to 162 (table 4). The nonmalignant diseases of the respiratory tract also showed a tendency towards an increased relative risk from increased cumulative expo- sure, but no dose-response relations were found for other causes of death.

Number of years in heavily exposed work ( $\geq 3$ dust scores) as a basis for categorization demonstrated an even greater dose-response relationship for lung cancer, increasing from an SMR of 47 to one of 
189 in the highest exposure category (table 5). The same tendency was seen for other diseases of the respiratory tract.

Table 6 displays the mortality pattern of a subcohort employed before 1939. The relative risk for lung cancer was relatively high $(\mathrm{SMR}=188)$. The marked undermortality from lung cancer among men employed in 1939-1954 could be explained by the fact that unproportionately many short-term employees entered the cohort during the Second World War.

The mortality pattern of cohort members ever employed in divisions where steam engines were repaired is displayed in table 7. A marked excess mortality from lung cancer $(\mathrm{SMR}=192)$ is shown for the highest exposure category. The relative risk for lung cancer was clearly higher in the two highest exposure categories within this subcohort compared to the same categories within the rest of the cohort (table 8).

In comparison to other asbestos-exposed cohorts there were few cases of mesotheliomas, only five. These have not been included among the lung cancer cases displayed in the tables. Three of the five cases had exposure to amphiboles from steam engine insulation noted in the records. The average length of life of the mesothelioma cases was 76 (range 70-82) years, the average latency time was 44 (range 30-57) years, and the average employment time was 32 (range 26-37) years.

\section{Discussion}

This study demonstrates a moderate increase in lung cancer mortality in comparison to the national death rates. The lung cancer risk increased by dust exposure categories in a consistent way, which can be interpreted as a dose-response relationship for asbestos exposure and the risk for lung cancer.

\section{Expected numbers from national death rates}

The overall mortality for the whole cohort was only $80 \%$ of that expected from the national death rates. Such an undermortality for work groups compared to the general population is often seen and has been referred to as the "healthy worker effect"' (8), but it signifies mainly a lack of validity in the comparison (14). Good health was required for employment at the workshop in this study, and this circumstance further limits the usefulness of national death rates. However, no other major source was available as a comparison group.

The age-standardized regional incidence of lung cancer was $72 \%$ of the national incidence in 19751980 (4). The SMR for lung cancer among the workers with low exposure was around 50 . The striking undermortality among the workers employed for less than one year can be attributed to short-term trainees who later became nonexposed salaried employees. All these indications point to the conclusion that this cohort would have experienced a lung cancer mortality distinctly below the national average if it had not been exposed to carcinogens.

The relative risks for the subcohort with the highest exposure should therefore be adjusted upwards in accordance with the low base-line risk from which the cohort started. The true risk for lung cancer in the category with the highest exposure may therefore be estimated to have been at least threefold that of the nonexposed workers.

\section{Smoking habits and lung cancer}

Smoking habits are important to consider when lung cancer risk is being studied. Information on the smoking habits of each individual was not available. However, within a sample of workers participating in a medical examination at the end of the 1970s, $36 \%$ had never smoked, and this percentage is a high proportion of nonsmokers in comparison to the general Swedish population.

The mortality from chronic obstructive lung disease could be used as another indication of the smoking habits in earlier decades. Tables $2-8$ show a marked undermortality from these diseases, a finding which supports the suggestion that the entire cohort had a higher proportion of nonsmokers than the general population also in earlier decades. In earlier decades smoking was not permitted in workplaces. This finding is in agreement with the low risk of lung cancer among the lowly exposed workers.

\section{Exposure standards and dose response}

The SMR for lung cancer was higher for the highest exposure category, which was determined on the basis of intensity, ie, dust score 3 or 4 , or cumulative exposure, ie, score times years, compared to categorization based on years of employment. Thus the dose-response relationship was stronger when the exposure standard was based on intensity rather than time.

The increased risks for lung cancer were comparatively modest, and this finding can be ascribed to a relatively moderate average exposure, as well as to the low amount of smoking among the workers. However, the prevalence of pleural plaques was about $50 \%$ in a group of 323 active and retired workers that participated in a voluntary, health examination in 1982 .

\section{Amphiboles and chrysotile}

The impact of different fiber types on lung cancer risk could not be studied in detail due to mixed exposures and lack of historical information. The highest relative risk for lung cancer was determined for a subcohort of men who had been employed in divi- 
Table 7. Observed and expected numbers of deaths before the age of 80 years for the subcohort who had worked at any time in the ment times and 20 years or more after the first date of employment (latency time). (SMR = standardized mortality ratio)

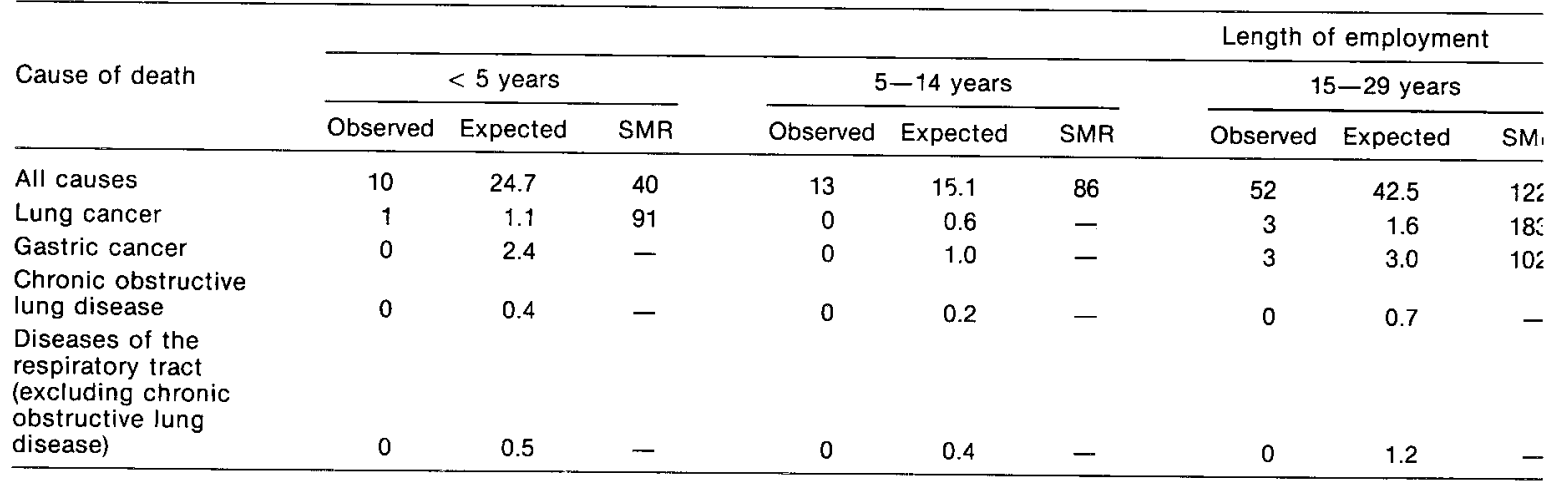

Table 8. Observed and expected numbers of deaths before the age of 80 years for the subcohort who had never worked in the ment time and 20 years or more after the first employment (latency time). (SMR = standardized mortality ratio)

\begin{tabular}{|c|c|c|c|c|c|c|c|c|c|}
\hline \multirow{3}{*}{ Cause of death } & & & & & & & \multicolumn{3}{|c|}{ Length of employment } \\
\hline & \multicolumn{3}{|c|}{$<5$ years } & \multicolumn{3}{|c|}{$5-14$ years } & \multicolumn{3}{|c|}{$15-29$ years } \\
\hline & Observed & Expected & SMR & Observed & Expected & SMR & Observed & Expected & SMF \\
\hline All causes & 52 & 84.8 & 61 & 30 & 44.0 & 68 & 114 & 105.5 & 108 \\
\hline Lung cancer & 0 & 3.8 & - & 0 & 1.9 & - & 3 & 3.7 & 81 \\
\hline Gastric cancer & 1 & 4.1 & 25 & 2 & 2.8 & 73 & 7 & 7.5 & 93 \\
\hline $\begin{array}{l}\text { Chronic obstructive } \\
\text { lung disease }\end{array}$ & 2 & 1.6 & 123 & 0 & 0.8 & - & 1 & 1.7 & 60 \\
\hline $\begin{array}{l}\text { Diseases of the } \\
\text { respiratory tract } \\
\text { (excluding chronic } \\
\text { obstructive lung }\end{array}$ & & & & & & & & & \\
\hline disease) & 1 & 2.0 & 50 & 0 & 1.1 & - & 6 & 3.4 & 179 \\
\hline
\end{tabular}

sions where the repair of steam engines took place and who had a total employment time of at least 30 years. This type of work involved exposure to amphiboles, which appear to be stronger carcinogens than chrysotile $(1,3,7)$.

Five cases of mesothelioma were observed. This is a low number compared to that of other large cohorts exposed to mixed types of asbestos. Three of the cases had exposure to amphiboles from steam engine repairs but, according to the records, two did not. Mesotheliomas have also been reported among men exposed mainly to chrysotile (5).

\section{Miscellaneous}

A weak increase in the number of deaths from pancreas cancer was observed among subjects employed $15-30$ years. It is possible that some cases of peritoneal mesothelioma might have been misdiagnosed as pancreas cancer (13). However the increased mortality from this disease was not related to the degree or length of exposure, and therefore a causal association is less likely.

In summary, this cohort study of 3297 male workers exposed to asbestos in a railroad workshop dem- onstrated a comparatively low overall increase in mortality from lung cancer in comparison to national death rates. However more than 30 years of mixed asbestos exposure was associated with a threefold increase in lung cancer risk. Five cases of mesothelioma were observed. A subcohort of men employed for less than 30 years and without exposure to the highest dust intensities had no apparent increase in the risk of lung cancer. Thus, in this railroad maintenance shop after the Second World War, employment, other than steam engine repairing, was not associated with any apparent increase in the risk of lung cancer. But this disease, and especially mesothelioma, requires long latency periods from the onset of exposure to diagnosis (death). Therefore many asbestos-related cancers may be found in the future follow-up of the cohort, and this possibility requires that the conclusions be interpreted with care.

\section{Acknowledgments}

We wish to thank the personnel of the industrial health organization and the staff management of the 
aintenance of steam boilers. Categories of exposure by employ-

\begin{tabular}{rrrrrrr}
\hline & $\geq 30$ years & & & \multicolumn{3}{c}{ Total } \\
\cline { 6 - 7 } bserved & Expected & SMR & & Observed & Expected & SMR \\
\hline 147 & 168.2 & 87 & & 222 & 250.5 & 89 \\
10 & 5.2 & 192 & & 14 & 8.5 & 164 \\
9 & 12.6 & 72 & & 12 & 18.9 & 63 \\
1 & 2.4 & 42 & & 1 & 3.7 & 27 \\
3 & & & & & \\
& & & & & & \\
\hline
\end{tabular}

aintenance of steam boilers. Categories of exposure by employ-

\begin{tabular}{rrrrrrr}
\hline & $\geq 30$ years & & & \multicolumn{3}{c}{ Total } \\
\cline { 1 - 4 } \cline { 5 - 7 } bserved & Expected & SMR & & Observed & Expected & SMR \\
\hline 168 & 242.2 & 69 & & 364 & 476.5 & 76 \\
10 & 7.8 & 128 & & 13 & 17.2 & 76 \\
8 & 17.8 & 45 & & 18 & 32.2 & 56 \\
1 & 3.5 & 28 & & 4 & 7.6 & 53 \\
& & & & & & \\
8 & 8.4 & 96 & & 15 & 14.9 & 101 \\
\hline
\end{tabular}

plant. Epidemiology assistant Mr G Brodin performed the data analyses, and Ms C Söderqvist prepared the manuscript.

This work has been supported by grants from the Swedish Work Environment Fund (no 79/342 \& 81-1122).

\section{References}

1. Acheson ED, Gardner MJ, Pippard EC, Grime LP. Mortality of two groups of women who manufactured gas masks from chrysotile and crocidolite asbestos: $\mathrm{A}$ 40 year follow-up. Br J Ind Med 39 (1982) 344-348.

2. Anjou C-G, Andersson K, Axelson O, Edling C, Samuelsson P-J, Wigertz O. A computer system for occupational health epidemiology. Department of Medical Engineering, Linköping University, Linköping 1980.

3. Berry G, Newhouse ML. Mortality of workers manufacturing friction materials using asbestos. $\mathrm{Br} \mathrm{J}$ Ind Med 40 (1983) 1-7.

4. Cancer Registry. Cancer incidence in Sweden. 1975-80. National Board of Health and Welfare, Stockholm 1983.

5. Dement JM, Harris RL, Symons MJ, Shy CM. Exposures and mortality among chrysotile asbestos workers: Part II Mortality. Am J Ind Med 4 (1983) $421-433$.

6. Lynch JR, Ayer HE, Johnson DL. The interrelationships of selected asbestos exposure indices. Am Ind Hyg Assoc J 31 (1970) 598-604.

7. McDonald AD, Fry JS, Woolley AJ, McDonald JC. Dust exposure and mortality in an American chrysotile asbestos friction products plant. $\mathrm{Br} \mathrm{J}$ Ind Med 41 (1984) 151-157.

8. McMichael AJ. Standardized mortality ratios and the "healthy worker effect': Scratching beneath the surface. J Occup Med 18 (1976) 165-168.

9. Nicholson WJ. Asbestos - The TLV approach. Ann NY Acad Sci 271 (1976) 152-169.

10. Nicholson WJ. Criteria document for Swedish occupational standards: Asbestos and inorganic fibers. Arbetarskyddsverket, Stockholm 1981. (Arbete och Hälsa 1981: 17).

11. Nicholson WJ, Perkel G, Selikoff IJ. Occupational exposure to asbestos: Population at risk and projected mortality - 1980-2030. Am J Ind Med 3 (1982) $259-311$.

12. Peters GA, Peters BJ. Source book on asbestos diseases: Medical, legal and engineering aspects. Garland STPM Press, New York \& London 1980. (Garland Safety Management Series).

13. Selikoff IJ, Hammond EC, Seidman H. Mortality experience of insulation workers in the United States and Canada. Ann NY Acad Sci 330 (1979) 91.

14. Wang J-D, Miettinen OS. Occupational mortality studies: Principles of validity. Scand J Work Environ Health 8 (1982) 153-158.

15. World Health Organization. International classification of diseases, 1965 revision. Issued by Socialstyrelsen, Stockholm 1968.

Received for publication: 1 October 1984 